\title{
AdVANCING Surface Water Pesticide EXPosure ASSESSMENTS FOR ECOSYSTEM PROTECTION
}

\author{
G. A. Fox， R. Muñoz-Carpena，B. Brooks，T. Hall
}

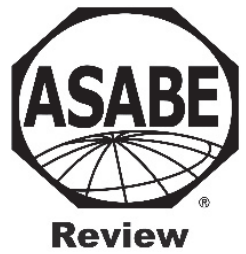

\section{HighLIGHTS}

- Crop protection and pest management programs continue to be integral for modern food production.

- Potential ecological impacts of pesticides must be assessed, and key mitigation practices adopted.

- Efforts are needed to advance surface water pesticide exposure assessments from field to landscape scales.

- Ensuring effective pesticide mitigation practices requires quantifying dynamic site-specific characteristics.

- Ecological assessments must improve prediction of adverse population and community-level outcomes.

ABSTRACT. As the global food demand increases, the use of pesticides will continue to increase with significant growth in low- and middle-income countries. Agricultural systems in which pesticides are used are complex with significant and often unknown biological, human, and physical-chemical interactions. These interactions include climate and hydrology, soil type, selection and use of best management practices, chemical fate and transport, application technology, and land use socioeconomics. The objective of this review article is to highlight key research opportunities identified from recent special meetings and workshops on advancing pesticide exposure assessments and mitigation. Research is needed in using advanced analytics and forensics to better understand the distribution of pesticides in the environment through novel monitoring and detection. Higher-tier modeling approaches can help inform monitoring a priori to better characterize pesticide distributions in the environment. Current pesticide exposure assessments are largely focused on the field or watershed scale, but advancements are needed to move toward landscape-scale analyses capable of analyzing for interacting ecosystems. Assessing the effects of complex, low-dose chemical mixtures on non-target aquatic organisms must advance with new quantitative high-throughput experimental methods focused on identifying interactions and not just additive effects. Field mitigation measures are currently considered as part of the pesticide exposure and risk assessment process using qualitative, fixedefficiency type approaches, but we specifically call for the use of existing quantitative tools moving forward. These mechanistic modeling and simulation tools can capture the inherent complexity within an agroecological system. There is a need for risk assessment to be more predictive of population and community-level impacts as part of environmentally relevant scenarios. Finally, it is imperative that professional societies take a more proactive role in promoting the transdisciplinary collaboration of biological and agricultural engineers with other disciplines contributing to advances in ecological risk assessment.

Keywords. Ecosystem, Exposure assessment, Landscape scale, Mechanistic modeling, Mitigation, Pesticides, Surface water quality.

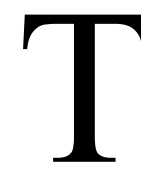

The world must increase food production as much as $50 \%$ to $60 \%$ to meet the anticipated population growth, estimated to be 9 to 10 billion by 2050 (FAO, 2019). To meet the growing demand, crop

Submitted for review on 25 July 2020 as manuscript number NRES 14225; approved for publication as an Invited Review Article by the Natural Resources \& Environmental Systems Community of ASABE on 5 November 2020 .

The authors are Garey A. Fox, Professor and Head, Department of Biological and Agricultural Engineering, North Carolina State University, Raleigh, North Carolina; Rafael Muñoz-Carpena, Professor, Department of Agricultural and Biological Engineering, University of Florida, Gainesville, Florida; Bryan Brooks, Distinguished Professor, Department of Environmental Science, and Director, Environmental Health Science Program, Baylor University, Waco, Texas; Tilghman Hall, Head of Environmental Safety North America, Bayer CropScience, Chesterfield, Missouri. Corresponding author: Garey Fox; 104 Weaver Labs, 3110 Faucette Drive, Raleigh, NC 27695; phone: 919-515-6700; e-mail: garey_fox@ncsu.edu. protection and pest management programs, including the use of pesticides, will remain a critical component of the food production system. As noted by the National Research Council (NRC, 2000), this future use is foreseeable because the benefits of pesticide use generally remain high relative to the risks, especially when there are no alternative pest management strategies. Chemicals today are safer with less environmental impact than previous synthetic organic pesticides due to chemical design, innovative chemical delivery systems, and precision application technology (NRC, 2000). However, concerns still exist regarding their fate and transport and the potential impact of these compounds on ecosystems and non-target populations including birds, bees, and aquatic species (Schäfer et al., 2019). Concerns also exist for public health, particularly in the face of climate change (Boxall et al., 2009). Global agricultural pesticide use continues to increase and recently passed 4 million 
metric tonnes annually with much of the increase in Asia and South America, while pesticide use in North America and Europe has remained relatively unchanged for the last 30 years (fig. 1). Such increased use in low- and middle-income countries must be effectively managed because numerous biodiversity hotspots exist in these regions around the world, and biodiversity losses are currently occurring faster than previously reported (IPBES, 2019).

Agricultural systems involving pesticide use and management are complex and are located within natural landscapes where different, and often unknown, components interact. These systems are very difficult to predict because interactions within the system often result in large uncertainty and lead to emergent behaviors, giving rise to a complex food-energy-water-social nexus problem. Specifically, in terms of pesticide use, consider the variations in land use influenced by socioeconomics and cultural and food preferences, and the diverse crops and field practices introduced within agroecological systems (fig. 2). All these factors can give rise to unique pests and insects. The complexity further increases when overlaid by changing climate and weather

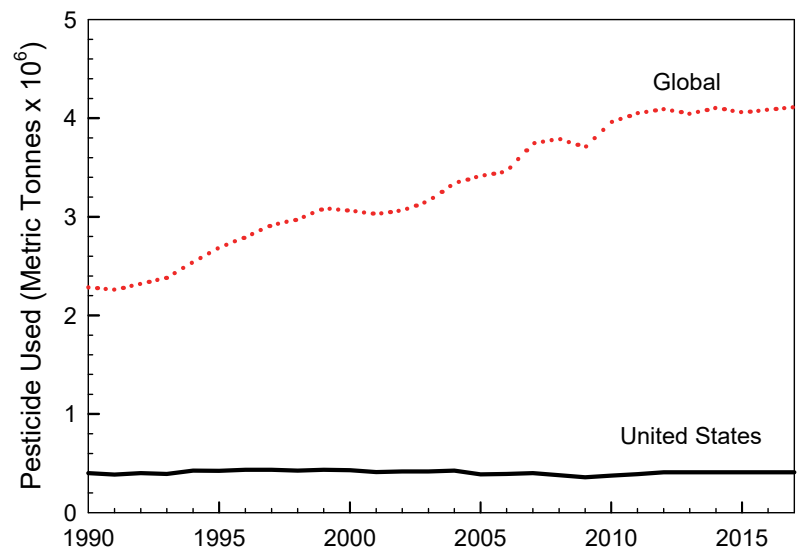

(a) patterns and the ensuing non-linear hydrological and contaminant transport responses. This inherent complexity of the integrated agroecological system makes it difficult to identify important processes and/or variables driving pesticide exposure.

In addition, the agricultural landscape will change significantly between now and 2050, with a global trend toward urban concentration with an unprecedented rate of people moving to cities. Approximately $70 \%$ of the 10 billion people on the planet by 2050 will be living in cities, and the population is expected to double during the 21 st century (UN, 2018). The agricultural community has a unique opportunity to consider the design of more sustainable food production systems, dependent on the reuse of water and nutrient resources from these urban centers, where $80 \%$ of global sewage goes untreated. For example, aquaculture production is growing faster than terrestrial agriculture (FAO, 2016), but here again management of source water quality and pesticide use will be important to support sustainable food production systems and environmental quality (Brooks and Conkle, 2019). As population and land use change, so

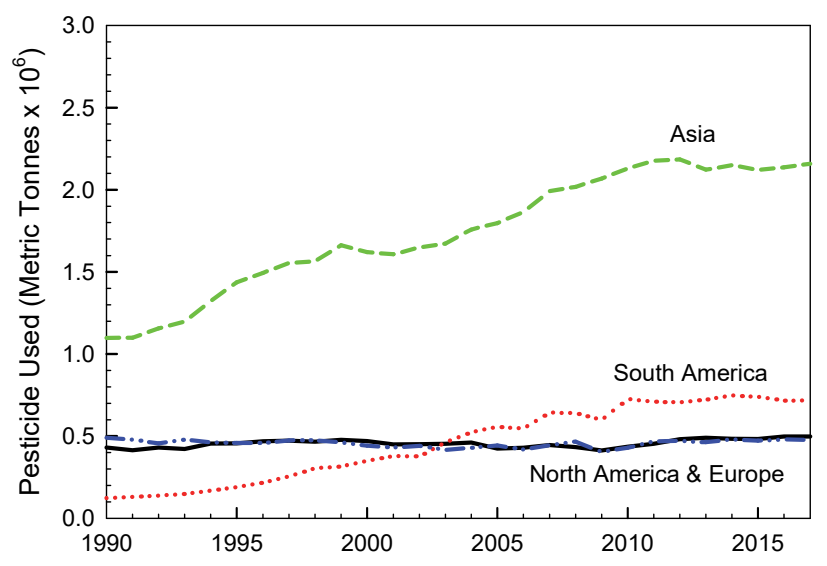

(b)

Figure 1. Global total agricultural pesticide use (1990-2017) comparing (a) global use to that in the U.S. and (b) for various regions of the world. Data from FAO pesticide use database (FAO, 2020).

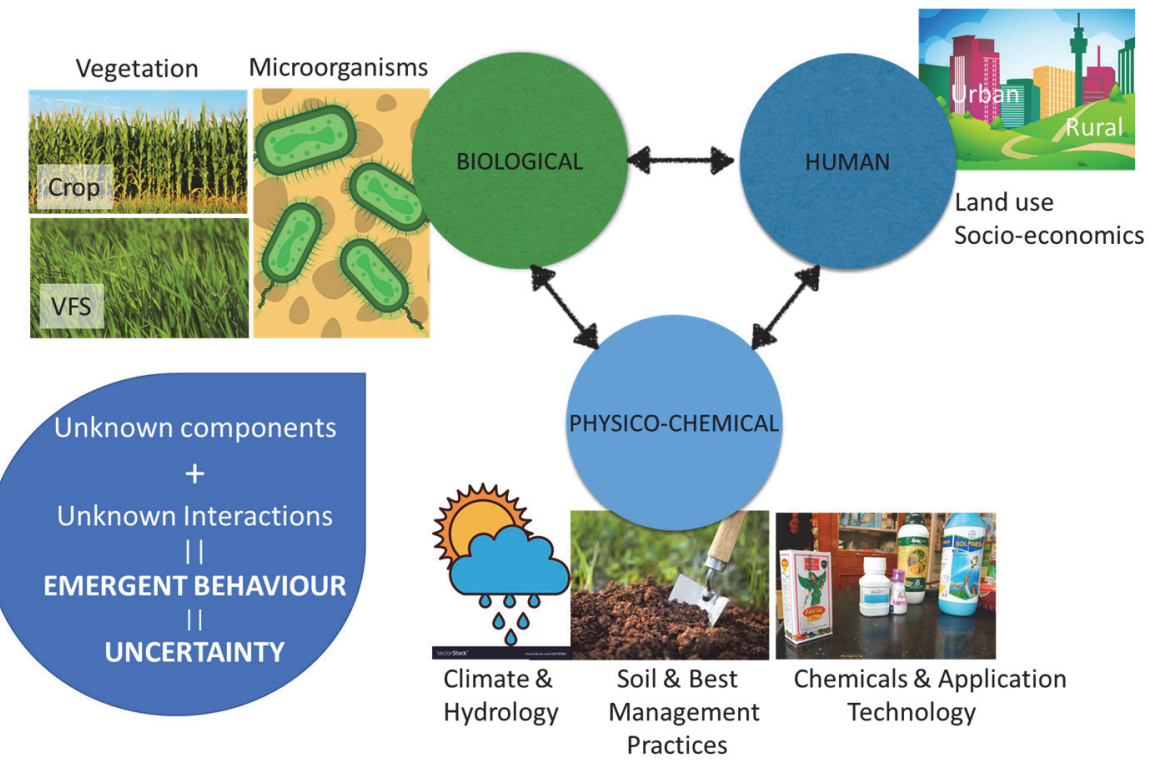

Figure 2. Depiction of the complexity around the assessment and management of pesticide exposures. 
will the uncertainties associated with ongoing climate change (Chaubey et al., 2016). These factors will deeply influence food production systems and the future need for pest control products.

In response to these challenges, key scientific and regulatory leaders in the field of pesticide risk assessment convened at the 2019 American Society of Agricultural and Biological Engineers (ASABE) Annual International Meeting in Boston, Massachusetts, in a special session titled "Pesticides in Freshwater Systems: Effects and Mitigation". This session focused on how pesticide use will help us meet the grand challenge associated with food production for the increasing population under land use and climate change uncertainties, while at the same time ensuring environmental protection. The presenters also put forth major opportunities for engineering and scientific research. This session has been followed by a series of 2020 workshops in the European Union (EU) on the quantitative mitigation of pesticides in surface runoff with vegetative filter strips (VFS). A first industry-targeted workshop was attended by 80 industry representatives of 27 different entities, followed by a second EU regulators and agencies workshop attended by 50 representatives from seven EU Southern Region countries. These workshops aimed at shifting the paradigm from qualitative, empirical pesticide mitigation approaches (i.e., qualitative generalization of experimental data to develop fixed reduction coefficients) to the adoption of processbased models as part of the higher-tier pesticide risk management regulatory framework. The objectives of this review article are to highlight the key takeaways from the ASABE special session and the ensuing EU workshops and discuss several research opportunities that should be pursued to help ensure the appropriate use of pesticides while at the same time managing environmental quality to meet the world's increasing food demand.

\section{PESTICIDE EXPOSURE AND RISK ASSESSMENT}

In the U.S., the Federal Insecticide, Fungicide, and Rodenticide Act (FIFRA) is a risk-benefit law that considers not only the risk of using chemicals but also the benefit of an intended use. One of the roles of the U.S. Environmental Protection Agency (USEPA) in risk assessment and management is to estimate chemical residues in the aquatic or terrestrial environments under the recommended pesticide use practices set on the product label (i.e., exposure assessment). The risk assessor must consider the potential of the resulting exposure for adversely influencing non-target organisms (i.e., effects assessment). Based on the risk evidence and benefits of the product, the risk manager decides whether or not to allow registration of new compounds or continued use of existing pesticides.

In the U.S., the EU, and most countries, pesticide exposure assessments aim at providing a reasonable upper bound estimate of pesticide concentrations in environments where non-target organisms may be present. An exposure assessment attempts to account for the major pathways of exposure: runoff, erosion, spray drift, volatility, and leaching. A tiered approach is used in which the higher tiers are successively finer screens with increasing realism and complexity that includes characterizations of variability and/or uncertainty (fig. 3). More specifically, at the lowest tier, the assessment uses simple inputs and outputs at low spatial and temporal resolutions. The initial tier focuses on pesticide properties and maximum use for generic areas and water bodies through simple screening tools. This provides an upper bound estimate of exposure.

If estimated exposures do not exceed toxicity thresholds in this first tier (with appropriate safety factors), then there is a high confidence of low risk. A second tier includes more realistic exposure assumptions and more detailed but still simplified modeling. The higher tiers, i.e., tier 3 for the USEPA and steps 3 and 4 for EU FOCUS (Linders et al., 2003), use detailed site-specific modeling and probabilistic exposure assumptions. For example, these tiers may consider more spatially explicit crop/pesticide use scenarios with either average or maximum use rates. Higher-tier assessments require more inputs, more complexity, and the analysis of detailed output. If estimated exposures exceed toxicity thresholds, then there may be risk concerns requiring mitigation.

As part of tiered assessments for aquatic organisms, the U.S. EPA Environmental Exposure and Effect Division (EFED) uses simulation models to predict estimated

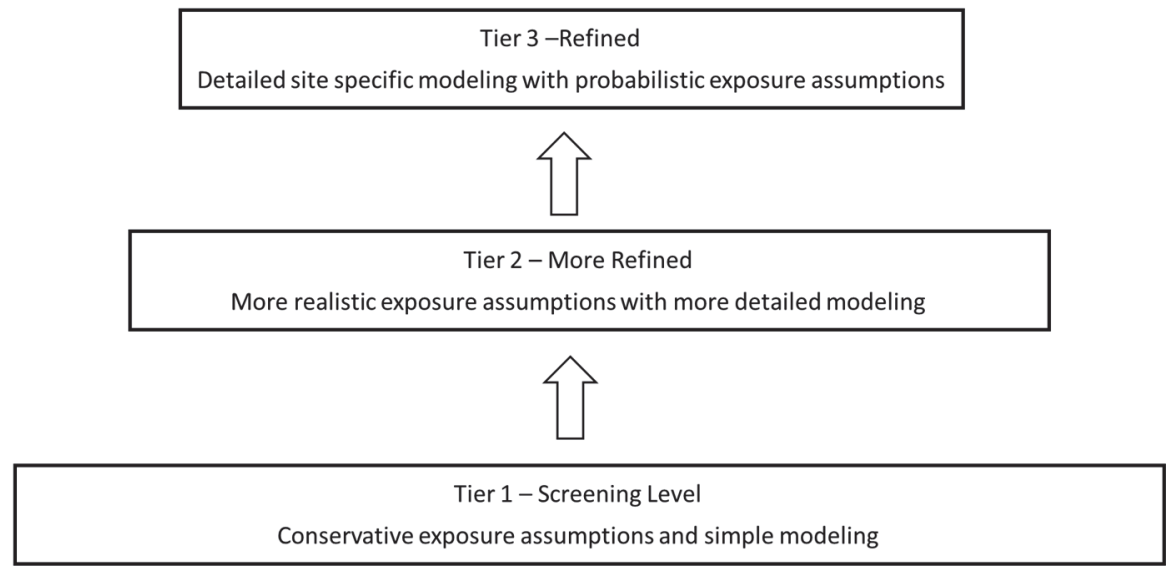

Figure 3. Tier screening approach from USEPA (2019). 
pesticide environmental exposure concentrations in surface water (USEPA, 2019). These exposure concentrations are then compared to toxicological endpoints to determine risks to aquatic systems. In this case, the toxicological endpoints are derived from single-species laboratory toxicity bioassays, which then can be integrated within probabilistic species sensitivity distributions and micro- or mesocosm model ecosystem experiments with population, community, and ecosystem level response variables (Rico et al., 2016). A similar framework is followed by EU FOCUS (Linders et al., 2003) and in other countries. The first tier uses a highly conservative screening tools and indices. Higher-tier assessments use modeling packages for pesticide fate and transport from an agricultural field into an adjacent water body and then the fate and redistribution among the solid and liquid phases within the receiving water body. The U.S. EPA created a set of benchmark scenarios for various crops that include variations in soil, weather, hydrology, and management practices (USEPA, 2019). As part of the exposure assessment, simulations are performed over 30 years using daily weather data and assuming maximum use rates. In the EU, four surface water exposure regions (R1 to R4) and six drainage scenarios (D1 to D6) are considered using 20-year daily simulations. Next, estimated environmental concentrations (EECs) are determined as 1 in 10-year annual maximum peaks or 4-d average concentrations for acute assessments, and 1 in 10-year annual maximum 21-d, 60-d, or 90$\mathrm{d}$ average concentrations for chronic risk assessments, depending on the target critical toxicological threshold.

While all tiered exposure assessments are intended to be sufficiently protective, adverse effects of pesticides are still commonly reported (Schäfer et al., 2019). Are we missing key drivers in the fate and transport mechanisms that need to be considered in actual landscapes or for in situ mitigation measures? How are we not accurately representing connectivity and intersections among landscapes and ecosystems (Schäfer et al., 2019)? What are the implications of climate variability and change and extreme weather events on fate and transport modeling predictions?

\section{RESEARCH OPPORTUNITIES}

\section{PESTICIDE MONITORING AND DETECTION}

In the U.S., the U.S. Geological Survey (USGS) through its National Water Quality Program measures pesticide concentrations in streams and lakes. Stone et al. (2014) reported that $61 \%$ of streams in agricultural areas, $46 \%$ in mixed land use areas, and $90 \%$ of urban streams had one or more pesticides that exceeded an aquatic-life benchmark for data from 2002-2011. Those authors highlighted the need for sampling in-stream sediment and the tissues of aquatic organisms and not just the water phase in rivers and streams that were part of the reported assessments above. Additional monitoring of various compartments of landscapes and ecosystems has been emphasized as a major need as part of the post-registration assessment of pesticides (Vijver et al., 2017).

A key research opportunity is how we use advanced analytics and forensics (e.g., chemical fingerprinting) for not only detecting pesticide residue levels within the environment and in food, but also for tracing and detecting the sources of pesticides and their transformation products. We currently monitor ecological systems infrequently and across limited spatial scales (Yagow et al., 2006). Limited capabilities exist currently for high-frequency water quality and ecological sampling for the occurrence of pesticides, and future research is needed to build upon recent advancements in biosensors and optical sensors (Verma and Bhardwaj, 2015; Yan et al., 2018). Research has documented the importance of high-frequency sampling on the uncertainty in assessing pollutant loads and concentrations (Birgand et al., 2010, 2011). We also need to understand spatial distributions and potential hotspots in the environment to determine pesticide use and predict potential impact more appropriately. Nowadays, non-target analyses using high-resolution mass spectrometry for pesticides, degradates, and metabolites present unique opportunities to further identify pesticides and define the exposure scenarios (Hollender et al., 2017) and exposomes (Vermeulen et al., 2020) of aquatic and terrestrial organisms under field-relevant conditions.

Instead of simply trying to identify key hotspots through brute force sampling and monitoring, which is largely lacking in most countries, higher-tier mechanistic modeling approaches can help identify expected distributions of chemical exposure. These modeling approaches can inform monitoring protocols by identifying a priori relevant locations, times, and key compartments within specific watersheds and receiving ecosystems that may be impacted by pesticides and their degradates. In this way, efficient higher-frequency monitoring can be informed through the integration of exposure modeling predictions for agroecological scenarios or site-specific characteristics.

\section{LANDSCAPE-SCALE ANALYSIS}

Aquatic exposure assessments aim to estimate pesticide levels in surface water that can account for variability in location and time. Ideally, the goal is to compare distributions of exposure concentrations with toxicity thresholds. What species are exposed to what pesticide residues, at what level, how long, how often, and where? These higher-tier assessments consider the pesticide properties, application, environmental conditions, and agronomic practices. However, most current exposure assessment scenarios are focused on the field scale, and mechanistic models that are used as part of the exposure assessment process do not capture the landscape scale, defined here as a heterogeneous land area at least a few kilometers wide and composed of interacting ecosystems (Forman and Godron, 1981). Note that watershed-scale models currently exist that simulate pesticide fate and transport, such as the Soil and Water Assessment Model (SWAT) as discussed by Winchell et al. (2018) and Wang et al. (2019). In its common form, SWAT is not a landscape model with interconnected ecosystem biomes but instead a watershed model. For computational efficiency, SWAT classifies unique hydrologic response units (HRUs) without direct connection to their individual position in the landscape and aggregates results at the subwatershed outlet. Future research is needed to determine how watershed-scale models could be adapted to produce realistic first-order approximations for landscape-level assessments (Rathjens et al., 2015). Using a landscape-level 
approach better mimics the agricultural landscape. Instead of managing a single farm (or representative field within) or subwatershed, we need to transition toward management at the ecological-relevant landscape scale.

The U.S. EPA is moving forward on improving the tiered aquatic exposure assessments by adding more tools for the refined tiers, including monitoring and providing more spatial and temporal context. With that said, landscape-level models could identify potential spatial areas of concern and spatial and temporal variations in biological uptake, which could then move toward potential impacts on the organism and population at the landscape level. A few examples exist in the literature of landscape-scale analyses in pesticide risk assessments. For example, Topping et al. (2015) used an agent-based simulation system and an existing beetle population model to evaluate the impact to population density and distribution at the landscape scale. They noted the unique complexity created by considering landscape structure and multi-seasonal pesticide effects. Chopin et al. (2019) reviewed several case studies using model-based scenario approaches for landscape-scale analyses. They specifically called for the integration of mechanistic models and spatially explicit drivers into future approaches, which aligns with a recent scientific opinion on pesticide risk assessment for reptiles and amphibians (Ockleford et al., 2018).

Another challenging aspect involved in a landscape-scale analysis of pesticide fate and transport involves being able to model and quantitatively assess pesticide mixtures. The difficulty with analyzing for mixtures is two-fold. First, on the effect side, ecotoxicological effects of complex mixtures, particularly for more common low-dose mixtures, are not well understood, in part because there are no standard methodological frameworks to account for them, and currently additive assumptions that assume negligible interactions are widely used (Backhaus and Faus, 2012; Alternburger et al., 2013). Recent research has proposed quantitative highthroughput experimental methods focused on identifying interactions and not just additive complex mixture effects (e.g., Rodea-Palomares et al., 2016), but adoption and advances are still critically needed. Second, on the exposure side, the challenge is accounting for interactions of the chemicals in the liquid and solid phases. If interactions are required, a multi-reaction simulation code is needed with much larger parametrization and computational requirements. Larger parametrization requirements can often result in increased prediction uncertainty (Muller et al., 2011).

Finally, landscape-scale analyses must be able to account for the increasing occurrence of extreme weather events (Chaubey et al., 2016; Fox, 2019). Pesticide transport after application in surface runoff depends significantly on the timing of the occurrence of precipitation following pesticide application and on the intensity of the precipitation event. More extreme weather events likely lead to greater runoff potential as a function of the runoff generated at the site, but also due to the occurrence of localized flooding that acts to connect elements of the landscape together. In addition, under increased precipitation, shallow water table conditions can become more predominant in the landscape, limiting the mitigation effect of natural riparian buffers or implanted VFS surrounding receiving surface water bodies (Fox et al.,
2018; Lauvernet and Muñoz-Carpena, 2018; MuñozCarpena et al., 2018).

\section{Population and Community-Level EFFECTS IN THE FIELD}

The first step of ecological risk assessment includes problem formulation, in which ecosystem protection goals are clearly defined. The population level of biological organization, along with important ecosystems services, represents the protection goal, with an exception for threatened and endangered species, for which individuals are protected due to their limited numbers. Because of cost and time constraints, regulatory agencies need to be able to quickly screen out compounds that may not cause a problem so that they can focus on those that may be an issue. Traditional assessments are typically based on comparisons of predicted environmental exposure concentrations to a regulatory accepted concentration derived from laboratory experiments, although higher-tier information from model ecosystem is occasionally available (Rico et al., 2016). More advanced predictive toxicology efforts, such as the Sequence Alignment to Predict Across Species Susceptibility (SeqAPASS) tool, are supporting identification of chemical attributes eliciting biological responses of common toxicological targets within the Adverse Outcome Pathway framework (Ankley et al., 2010; LaLone et al., 2016). Because pesticides are intentionally designed as biologically active substances, which routinely target specific receptors or enzymes to elicit desired outcomes, identifying evolutionary conservation of toxicological targets across species promises to support streamlined assessments by identifying specifically susceptible organisms a priori and thus reducing uncertainty (Brooks et al., 2020).

Whereas risk assessors commonly examine populationrelevant responses (e.g., survival, growth, reproduction) of individual species from bioassays performed in the laboratory, there remains a need to become more predictive of population and community-level perturbations under environmentally relevant scenarios in the field (fig. 4). For example, when we consider potentially susceptible watersheds and the chemicals that we currently use (or plan to), we must consider the agricultural practices in those areas along with sitespecific environmental conditions influencing fate, transport, and exposure scenarios in the region. Therefore, advanced models are needed for pesticides that predict not just aquatic concentrations for a target species, but when combined with ecologically relevant models and scenarios can predict non-target acute and chronic adverse outcomes of populations and communities within potentially affected ecosystems (fig. 4). Herein, emerging tools, including environmental DNA to identify population and community structure (Zhang, 2019), hold much promise if further developed.

Understanding fate, transport, uptake, recovery, and interaction mechanisms is similarly key to reducing uncertainty in risk assessment, especially in terms of being able to identify sensitive taxonomy. From an exposure analysis perspective, hydrological and pesticide fate and transport models need to be at the landscape and catchment scales but focused on the best available science, which can then be linked to toxicokinetic-toxicodynamic (TKTD) models and then 


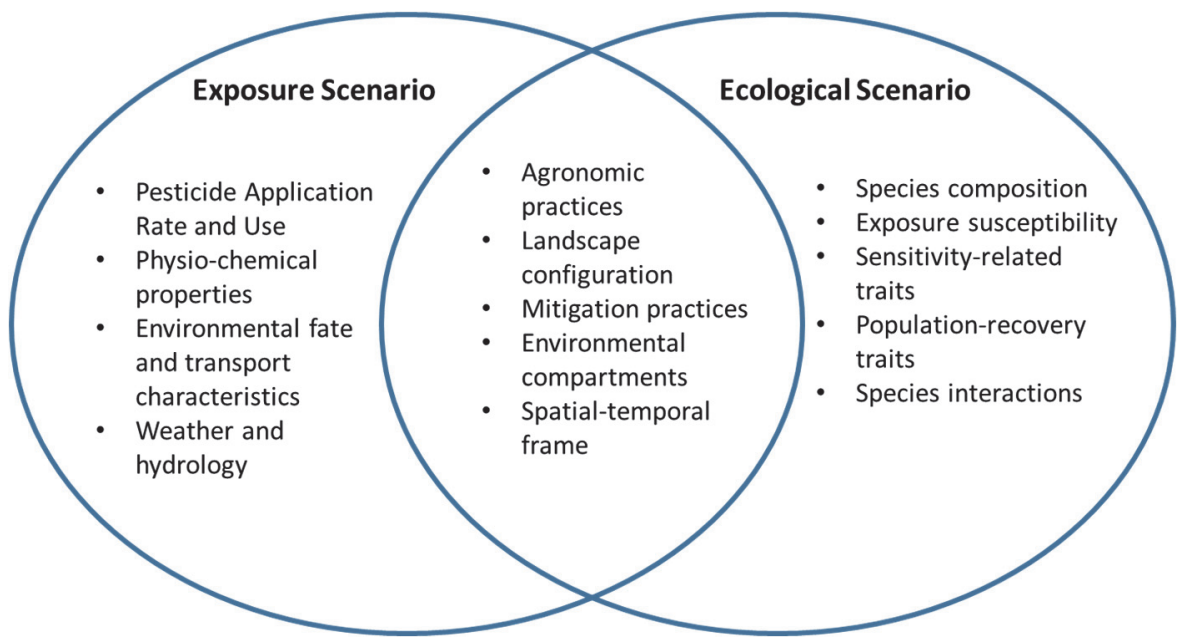

Figure 4. Combined population and community-level exposure and ecological scenarios for pesticide environmental risk assessment. Modified from Rico et al. (2016).

back to population-level effects from an ecological perspective (Forbes et al., 2016). Such modeling advances may indicate areas where populations and communities may or may not be affected, depending of course on agricultural practices, landscape characteristics, and/or weather patterns.

Agricultural and biological engineers should strengthen collaborations with other disciplines to bring their mechanistic and process-based understanding to advance exposure assessments. Engineers are strong at integrating system components and modeling fate and transport processes at a range of spatial scales (Cibin et al., 2018; Senaviratne et al., 2018; Fox, 2019). This mechanistic approach ultimately enables the quantification of exposure concentrations through runoff, drainage, and drift pathways. Other disciplines have separately advanced mechanistic modeling of the effects on populations and communities in the environment. Through collaboration and multidisciplinary efforts, a great opportunity emerges now to couple formally the assessments of exposure and effects to field-relevant population and communities (Chopin et al., 2019).

\section{Mitigation Practices}

The higher-tier refinements discussed above may consider the impacts of conservation practices or best management practices (BMPs) as mitigation strategies (USDA, 2005). Risk management of pesticides in runoff can be achieved through on-site and off-site practices. On-site practices include several in-field soil and water conservation practices that reduce surface runoff and erosion and correspondingly reduce pesticides in runoff. Off-site practices serve as a last line of defense and include VFS, riparian buffers, constructed and natural wetlands, and other practices. In fact, there is interest in how best management practices working in conjunction can be used for enhanced mitigation. Overall, there is a need to further explore agronomic and conservation practices and BMPs when refining risk assessments; for example, the use of conservation tillage and microdams in corn and potato (Sittig et al., 2020). These and other agronomic and mitigation practices are important components to ensure realism of the higher-tier assessments (Muñoz-Carpena et al., 2015, 2019).
For example, consider commonly used riparian buffers and VFS (Sabbagh et al., 2010; Webber et al., 2018; Gupta et al., 2019; Momm et al., 2019; Muñoz-Carpena et al., 2019). Much debate remains regarding how to quantitatively predict the performance of buffers or VFS (i.e., under what conditions they work efficiently) to mitigate pesticide surface runoff and ensure risk reduction. Recent research has clearly demonstrated that VFS length is not a good predictor of effectiveness (Sabbagh et al., 2009; Fox and Sabbagh, 2009); instead, performance depends on the hydrology, erosion and sedimentation, vegetation, and pesticide degradation and sorption coefficients (Fox et al., 2010; MuñozCarpena et al., 2010). As an illustration, the range of potential pesticide surface runoff mitigation by a $10 \mathrm{~m}$ VFS with moderate sorption potential has shown to range between $10 \%$ and $100 \%$ depending on the application site characteristics (hydrology, sedimentology, and pesticide used) (Reichenberger et al., 2019) and the incoming runoff and precipitation (Sabbagh et al., 2010) (fig. 5).

In this context, the use of empirical fixed factors to quantify VFS performance, e.g., EU FOCUS Landscape and Mitigation (L\&M) factors (Linders et al., 2003), while simple in application, is often insufficient to represent specific conditions of assessment scenarios and quite uncertain. Should a risk assessor be comfortable in using an assumed $60 \%$ fixed efficiency for this mitigation practice? A fixed efficiency approach may underestimate or even worse overestimate the benefit of the mitigation strategy. Quantitative mitigation is possible through process-based approaches based on modeling tools such as the Vegetative Filter Strip MODeling (VFSMOD) system (Fox, 2019; Muñoz-Carpena et al., 1999, 2019). Sur et al. (2019) compared EU FOCUS L\&M fixed factors with VFSMOD for a wide range of EU hightier pesticide assessment scenarios. They concluded that VFSMOD described VFS mitigation performance (runoff, sediment, and pesticide trapping) more realistically than the EU FOCUS L\&M fixed efficiency approach. Therefore, this fixed efficiency approach should be used instead as an initial screening approach within EU Step 3 higher-tier assessments. In contrast to EU FOCUS L\&M, VFSMOD integrated within the highest-tier EU Step 4 Surface Water 


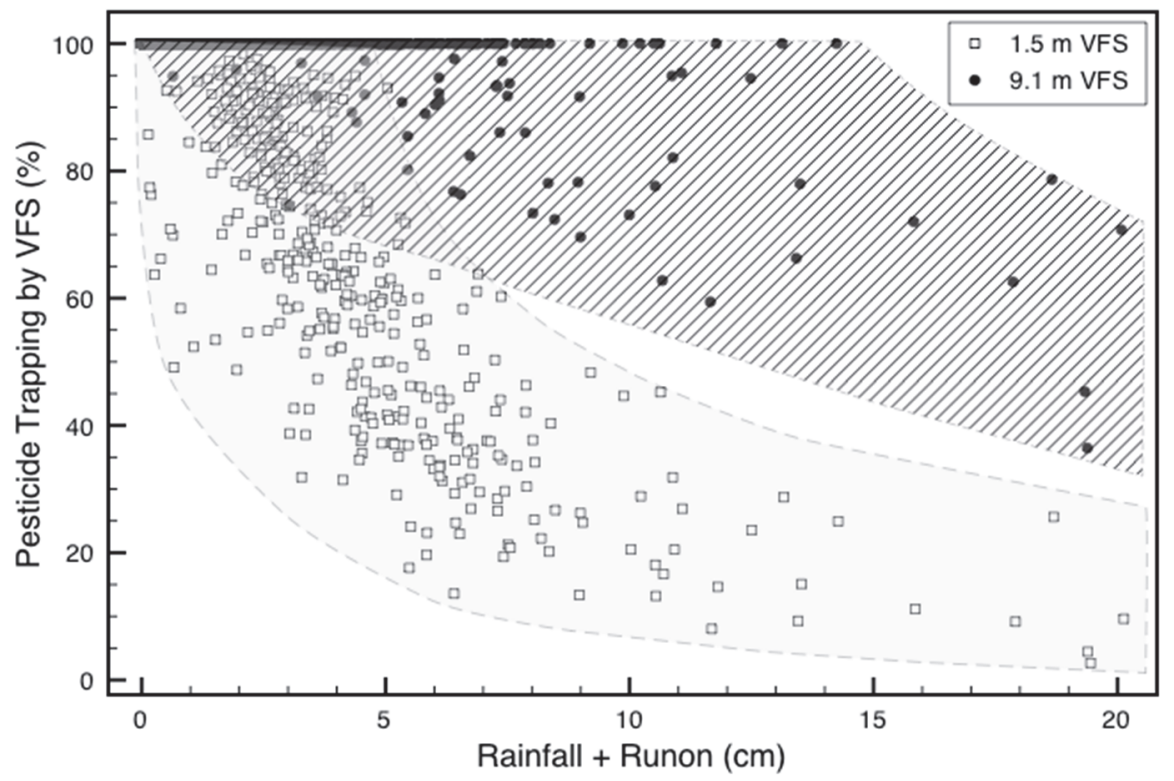

Figure 5. Nonlinear relationship between cumulative rainfall and run-on $(\mathrm{cm})$ entering a vegetative filter strip (VFS) versus the pesticide reduction (\%) relative to two different VFS lengths $(1.5$ and $9.1 \mathrm{~m})$ as predicted by VFSMOD-W for a clay loam soil with $6 \%$ slope. Reprinted with permission from Sabbagh et al. (2010). Copyright 2010 American Chemical Society.

Assessment eNabler (SWAN) tool can more realistically predict low VFS efficiency for large rainfall/runoff events and events dominated by snowmelt. However, adoption of these and other advanced technologies by risk assessors and regulators remains a barrier at the global level (Topping et al., 2020).

The conclusions from the aforementioned 2020 EU VFS Pesticide Mitigation Workshops offer important insights on the need and path forward for adoption of quantitative mitigation of pesticides:

- It is the smart thing to do. Cases that pass the regulatory process based on stringent science-based quantitative mitigation offer the registrant and agencies a transparent, sound decision on why they should pass.

- It is the right thing to do. Ultimately, if risks are determined to be severe, then decisions are necessary to avoid or mitigate these risks. Failing to recognize and appropriately manage the risk can open fronts for litigation and responsibilities.

- Thus, it is a win-win-win situation for regulators and the public in terms of improving water quality and for the industry in terms of identifying critical uses that require mitigation.

- While all models are wrong, widely published and validated models like VFSMOD that represent the state-of-science in VFS and riparian buffer efficiency modeling must be integrated in current higher-tier pesticide exposure assessments.

- A further aspect is that in the future we will see more digitalization in farming that will likely impact sitespecific risk assessments. In addition to field scenarios, diagnosis and mitigation advice will likely be needed about the spatial distribution of the compounds. Spatially distributed, physically based mechanistic models and components must be developed and coupled to allow the simulation of field-specific mitigation effects using high-resolution precision farming data.

As discussed earlier, researchers continue to contribute to the development of new mitigation practices and parameterization of existing and new practices into exposure assessment models (Fox and Muñoz-Carpena, 2018). However, adoption by risk assessors remains a major hurdle. Quantitative mitigation approaches, while more realistic and capable of incorporating nominal conditions of the design and alterations due to the lack of maintenance or extreme events, are more difficult to implement than assuming a simplistic fixed efficiency for the mitigation practice. Outreach and extension efforts are critically needed to engage the risk management community in the need to move forward with these more advanced approaches and use the best available science and engineering. Similarly, demonstrating effective implementation of such advanced modeling and management approaches, especially in the face of climate change and during extreme events, promises to further support realistic refinement during risk assessments.

\section{COMPlex Systems Analysis Calls FOR ENGINEERING EXPERTISE}

The naturalist John Muir warned us about the challenge we face when studying any component within nature's complex systems: "When we try to pick out anything by itself, we find it hitched to everything else in the universe." Future questions about pesticide use and mitigation are moving toward larger scales. As the scale and the need for refinement of the problem increase, the degree of complexity and the uncertainty increase, as does the need to integrate important system components to reproduce the system dynamics and emergent behaviors. However, there exists a practical limit to this continuously increasing model complication strategy, where the aggregated uncertainty of the additional system 
components can be large and outweigh the benefit of including these until the model is no longer relevant for the intended use (Muller et al., 2011).

We challenge biological and agricultural engineers and their collaborators to use integrated systems thinking and data tools to capture this complex behavior and then analyze the important factors and driving variables. How can artificial intelligence (AI) through machine learning and deep learning be used to advance our efforts? For example, while AI can be quite efficient at making predictions in cases with high dimensionality, the approaches involve mostly black boxes. Could AI techniques be used as screening tools and to identify key factors to inform a mechanistic modeling approach? How can we better use field data at the unprecedented high spatial and temporal resolutions provided by new monitoring and remote sensing technologies and incorporate big data (e.g., ecological genomics) and data analytics for improving ecological risk assessments and decisionmaking? The National Research Council (NRC, 2000) specifically called for land grant universities to pursue systemsbased interdisciplinary research and teaching focused on applied biology and risk evaluation. We need to understand the system and underlying processes and then identify effective use and mitigation strategies to reduce exposure to non-target systems and species. How do we integrate the best possible science to inform decision-making, such as landscapescale approaches to reduce uncertainty in predicting the impacts of management actions (Topping et al., 2019)? For an engineering approach to be relevant and impactful, collaboration among engineers and other disciplines is required more today than ever before. This will require coalescing diverse information representing multiple data streams from multiple levels of biological organization into coherent hazard frameworks.

Pesticide use, through its connections to environmental quality and contamination, influences the achievement of several of the UN Sustainable Development Goals, including SDG 11 (Sustainable cities and communities) and SDG 15 (Life on land). As noted above, biodiversity is declining faster than at any time in history. Can our professional communities work together more closely in these efforts to design and predict the biological and physio-chemical properties of chemicals during development to minimize environmental hazards? While we have focused on managing pesticide risks by reducing exposure, there are outstanding opportunities to collaborate among specialists in a holistic manner to design substances that are more bioavailable and less hazardous. Such work will require biological and agricultural engineers to collaborate with analytical chemists and molecular geneticists to design safer compounds and with environmental and social scientists to identify the potential risks of their use.

Biological and agricultural engineers must forge closer relationships with organizations that are leading efforts in ecological risk assessment, such as the AGRO and Environmental Chemistry Divisions of the American Chemical Society (ACS), Society of Environmental Toxicology and Chemistry (SETAC), European Crop Protection Association (ECPA), Soil and Water Conservation Society (SWCS), and Soil Science Society of America (SSSA), among others. In the EU, the MAgPIE (Mitigating the risk of Ag Plant protection products In the Environment) project hosted by SETAC provides a platform for EU regulatory, industry, and producers to identify and implement pesticide mitigation practices (Brown et al., 2017). Collaborative efforts like the Global Horizon Scanning project (Brooks et al., 2013) are already yielding a number of highly relevant environmental quality research questions from North America, Europe, Latin America, Oceania, and Asia related to crop protection, pest management, and the food-energy-water nexus.

In another collaborative example, following the $2020 \mathrm{EU}$ VFS workshops, new committees and activities have been launched to inform country authorities and the EU Commission on the adoption of new technologies such as SWANVFSMOD for quantitative mitigation approaches. EU State members require harmonization of the mitigation practices used in high-tier regulatory assessments that incorporate specific crops and agroecological system characteristics for each region, including Mediterranean versus northern conditions. Another important aspect required is the development of proper implementation and maintenance of mitigation practices like VFS and how these practices can be included within existing assessment scenarios in a user-friendly and reproducible way.

A similarly large-scale effort around the regulatory adoption of VFS is currently underway in North America with the U.S. EPA, Canada Pest Management Regulatory Agency (PMRA), California Department of Pesticide Regulation (DPR), and USDA. More specifically, North Carolina State University's Center of Excellence for Regulatory Science in Agriculture (CERSA) and Bayer CropScience have organized workshops on incorporating the benefits of VFS into risk assessment and risk management of pesticides. The workshops were designed to bring together experts to explore the state-of-the-art knowledge with respect to function, benefits, and modeling tools to simulate VFS at field and watershed scales. Additional efforts in organizing follow-up workshops should be encouraged.

\section{Conclusions}

As noted by the National Research Council (NRC, 2000), a priority approach for increasing the benefits of and reducing risks related to pesticide use is by reducing "adverse offtarget effects by judicious choice of chemical agents, implementation of precision application technology, and determination of economic and environmental impact thresholds for pesticide use in more agricultural systems." In the future, pesticide use and regulation must be explicit in ecological protection goals with a consensus among all stakeholders and show how users can protect the environment. Opportunities abound for scientists and engineers to help further ensure the production of a viable long-term food supply and mitigate the environmental impacts of pesticides, particularly in low- and middle-income countries, where pesticide use is outpacing development of robust environmental management systems. Such opportunities include the following research tasks: 
- Incorporate spatial and temporal contexts into exposure modeling and develop exposure scenarios that better reflect not just the field or watershed but also the landscape conditions, account for variability across the pesticide use areas, and consider a full spectrum of water bodies and habitats.

- Use novel high-frequency monitoring technology for the quantitative characterization of measured concentrations and their associated uncertainties.

- Quantify the interaction effects of complex chemical mixtures in the environment through the application of novel quantitative high-throughput experimental methods.

- Account for existing and potential agronomic and mitigation practices through mechanistic modeling in risk assessment instead of relying on simpler fixed efficiency qualitative approaches that oversimplify the complexity of the system.

- Collaborate with computational, environmental, and analytical chemists, molecular geneticists, ecologists, and social scientists to design chemicals and adoptable, cost-effective mitigation practices to minimize environmental hazards.

Biological and agricultural engineers, who operate at the crossroads between engineering and agroecological systems, need to be at the forefront of these advancements in collaboration with other disciplines and key professional and scientific societies.

\section{ACKNOWLEDGMENTS}

The authors acknowledge financial support through the ASABE Initiative Fund in support of travel costs for presenters at the 2019 ASABE Annual International Meeting in Boston, Massachusetts, in July 2019. We also acknowledge presentations at the ASABE special session by Nelson Thurman, Environmental Fate and Effects Division, USEPA Office of Pesticide Programs, and Sheryl Kunickis, USDA Office of Pest Management Policy. Garey Fox and Rafael Muñoz-Carpena also acknowledge funding support provided by the USDA-NIFA through Project No. 2016-6701926855 .

\section{REFERENCES}

Altenburger, R., Backhaus, T., Boedeker, W., Faust, M., \& Scholze, M. (2013). Simplifying complexity: Mixture toxicity assessment in the last 20 years. Environ. Toxicol. Chem., 32(8), 1685-1687. https://doi.org/10.1002/etc.2294

Ankley, G. T., Bennett, R. S., Erickson, R. J., Hoff, D. J., Hornung, M. W., Johnson, R. D., ... Villeneuve, D. L. (2010). Adverse outcome pathways: A conceptual framework to support ecotoxicology research and risk assessment. Environ. Toxicol. Chem., 29(3), 730-741. https://doi.org/10.1002/etc.34

Backhaus, T., \& Faust, M. (2012). Predictive environmental risk assessment of chemical mixtures: A conceptual framework. Environ. Sci. Tech., 46(5), 2564-2573. https://doi.org/10.1021/es2034125

Birgand, F., Faucheux, C., Gruau, G., Augeard, B., Moatar, F., \& Bordenave, P. (2010). Uncertainties in assessing annual nitrate loads and concentration indicators: Part 1. Impact of sampling frequency and load estimation algorithms. Trans. ASABE, 53(2), 437-446. https://doi.org/10.13031/2013.29584

Birgand, F., Faucheux, C., Gruau, G., Moatar, F., \& Meybeck, M. (2011). Uncertainties in assessing annual nitrate loads and concentration indicators: Part 2. Deriving sampling frequency charts in Brittany, France. Trans. ASABE, 54(1), 93-104. https://doi.org/10.13031/2013.36263

Boxall, A. B. A., Hardy, A., Beulke, S., Boucard, T., Burgin, L., Falloon, P. D., ... Williams, R. J. (2009). Impacts of climate change on indirect human exposure to pathogens and chemicals from agriculture. Environ. Health Perspect., 117(4), 508-514. https://doi.org/10.1289/ehp.0800084

Brooks, B. W., \& Conkle, J. L. (2019). Perspectives on aquaculture, urbanization, and water quality. Comp. Biochem. Physiol. C, 217, 1-4. https://doi.org/10.1016/j.cbpc.2018.11.014

Brooks, B. W., Ankley, G. T., Boxall, A. B. A., \& Rudd, M. A. (2013). Toward sustainable environmental quality: A call to prioritize global research needs. Integ. Environ. Assess. Mgmt., 9(2), 179-180. https://doi.org/10.1002/ieam.1411

Brooks, B. W., Sabo-Attwood, T., Choi, K., Kim, S., Kostal, J., LaLone, C. A., ... Zhang, X. (2020). Toxicology advances for 21st century chemical pollution. One Earth, 2(4), 312-316. https://doi.org/10.1016/j.oneear.2020.04.007

Brown, C., Laabs, V., Mackay, N., Alix, A., Bradascio, R., Dyson, J., ... Roepke, B. (2017). Risk mitigation measures to protect surface waters. Proc. MAgPIE Workshop Mitigating the Risks of Plant Protection Products in the Environment (pp. 71-116). SETAC.

Chaubey, I., Bosch, D. D., Muñoz-Carpena, R., Harmel, R. D., Douglas-Mankin, K. R., Nejadhashemi, A. P., ... Shirmohammadi, A. (2016). Climate change: A call for adaptation and mitigation strategies. Trans. ASABE, 59(6), 17091713. https://doi.org/10.13031/trans.59.12138

Chopin, P., Bergkvist, G., \& Hossard, L. (2019). Modelling biodiversity change in agricultural landscape scenarios: A review and prospects for future research. Biol. Conserv., 235, 117. https://doi.org/10.1016/j.biocon.2019.03.046

Cibin, R., Chaubey, I., Helmers, M. J., Sudheer, K. P., White, M. J., \& Arnold, J. G. (2018). An improved representation of vegetative filter strips in SWAT. Trans. ASABE, 61(3), 10171024. https://doi.org/10.13031/trans.12661

FAO. (2016). The state of world fisheries and aquaculture 2016: Contributing to food security and nutrition for all. Rome, Italy: United Nations FAO. Retrieved from http://www.fao.org/publications/sofia/2016/en/

FAO. (2019). FAO cereal supply and demand brief. Rome, Italy: United Nations FAO. Retrieved from http://www.fao.org/worldfoodsituation/csdb/en/

FAO. (2020). Pesticides use database. Rome, Italy: United Nations FAO. Retrieved from http://www.fao.org/faostat/en/?\#data/RP

Forbes, V. E., Galic, N., Schmolke, A., Vavra, J., Pastorok, R., \& Thorbek, P. (2016). Assessing the risks of pesticides to threatened and endangered species using population modeling: A critical review and recommendations for future work. Environ. Toxicol. Chem., 35(8), 1904-1913. https://doi.org/10.1002/etc.3440

Forman, R. T. T., \& Godron, M. (1981). Patches and structural components for a landscape ecology. BioScience, 31(10), 733740. https://doi.org/10.2307/1308780

Fox, G. A. (2019). Process-based design strengthens the analysis of stream and floodplain systems under a changing climate. Trans. ASABE, 62(6), 1735-1742. https://doi.org/10.13031/trans.13594

Fox, G. A., \& Muñoz-Carpena, R. (2018). Engineering the design of buffers and vegetative filter strips. Resource, 25(2), 4-5.

Fox, G. A., \& Sabbagh, G. J. (2009). Comment on "Major factors influencing the efficacy of vegetated buffers on sediment 
trapping: A review and analysis”. J. Environ. Qual., 38(1), 1-3. https://doi.org/10.2134/jeq2009.0001le

Fox, G. A., Muñoz-Carpena, R., \& Purvis, R. A. (2018). Controlled laboratory experiments and modeling of vegetative filter strips with shallow water tables. J. Hydrol., 556, 1-9. https://doi.org/10.1016/j.jhydrol.2017.10.069

Fox, G. A., Muñoz-Carpena, R., \& Sabbagh, G. J. (2010). Influence of flow concentration on parameter importance and prediction uncertainty of pesticide trapping by vegetative filter strips. $J$. Hydrol., 384(1), 164-173. https://doi.org/10.1016/j.jhydrol.2010.01.020

Gupta, A. K., Rudra, R. P., Gharabaghi, B., Goel, P. K., Sebti, S., Shukla, R., \& Daggupati, P. (2019). A modeling approach for evaluating watershed-scale water quality benefits of vegetative filter strip: A case study in Ontario. Appl. Eng. Agric., 35(3), 271-281. https://doi.org/10.13031/aea.13121

Hollender, J., Schymanski, E. L., Singer, H. P., \& Ferguson, P. L. (2017). Nontarget screening with high-resolution mass spectrometry in the environment: Ready to go? Environ. Sci. Tech., 51(20), 11505-11512.

https://doi.org/10.1021/acs.est.7b02184

IPBES. (2019). The global assessment report on biodiversity and ecosystem services. Bonn, Germany: Intergovernmental Science-Policy Platform on Biodiversity and Ecosystem Services. Retrieved from https://ipbes.net/global-assessment

LaLone, C. A., Villeneuve, D. L., Lyons, D., Helgen, H. W., Robinson, S. L., Swintek, J. A., ... Ankley, G. T. (2016). Sequence alignment to predict across species susceptibility (SeqAPASS): A web-based tool for addressing the challenges of cross-species extrapolation of chemical toxicity. Toxicol. Sci., 153(2), 228-245. https://doi.org/10.1093/toxsci/kfw119

Lauvernet, C., \& Muñoz-Carpena, R. (2018). Shallow water table effects on water, sediment, and pesticide transport in vegetative filter strips: Part 2. Model coupling, application, factor importance, and uncertainty. Hydrol. Earth Syst. Sci., 22(1), 7187. https://doi.org/10.5194/hess-22-71-2018

Linders, J., Adriaanse, P., Allen, R., Capri, E., Gouy, V., Hollis, J., ..., Yon, D. (2003). FOCUS surface water scenarios in the EU evaluation process under 91/414/EEC. Report prepared by the FOCUS Working Group on Surface Water Scenarios. EU Document Reference SANCO/4802/2001-rev.2. Brussels, Belgium: European Commission, Health and Consumer Protection Directorate-General.

Momm, H. G., Yasarer, L. M., Bingner, R. L., Wells, R. R., \& Kunhle, R. A. (2019). Evaluation of sediment load reduction by natural riparian vegetation in the Goodwin Creek watershed. Trans. ASABE, 62(5), 1325-1342. https://doi.org/10.13031/trans.13492

Muller, S., Muñoz-Carpena, R., \& Kiker, G. (2011). Model relevance: Frameworks for exploring the complexity-sensitivityuncertainty trilemma. In I. Linkov \& T. S. Bridges (Eds.), Climate: Global change and local adaptation (pp. 35-65). Boston, MA: Springer. https://doi.org/10.1007/978-94-0071770-1_4

Muñoz-Carpena, R., Fox, G. A., \& Sabbagh, G. J. (2010). Parameter importance and uncertainty in predicting runoff pesticide reduction with filter strips. J. Environ. Qual., 39(2), 630-641. https://doi.org/10.2134/jeq2009.0300

Muñoz-Carpena, R., Lauvernet, C., \& Carluer, N. (2018). Shallow water table effects on water, sediment, and pesticide transport in vegetative filter strips: Part 1 . Nonuniform infiltration and soil water redistribution. Hydrol. Earth Syst. Sci., 22(1), 53-70. https://doi.org/10.5194/hess-22-53-2018

Muñoz-Carpena, R., Parsons, J. E., \& Gilliam, J. W. (1999). Modeling hydrology and sediment transport in vegetative filter strips. J. Hydrol., 214(1), 111-129. https://doi.org/10.1016/S0022-1694(98)00272-8

Muñoz-Carpena, R., Ritter, A., \& Fox, G. A. (2019). Comparison of empirical and mechanistic equations for vegetative filter strip pesticide mitigation in long-term environmental exposure assessments. Water Res., 165, article 114983. https://doi.org/10.1016/j.watres.2019.114983

Muñoz-Carpena, R., Ritter, A., Fox, G. A., \& Perez-Ovilla, O. (2015). Does mechanistic modeling of filter strip pesticide mass balance and degradation processes affect environmental exposure assessments? Chemosphere, 139, 410-421. https://doi.org/10.1016/j.chemosphere.2015.07.010

NRC. (2000). The future role of pesticides in U.S. agriculture. Washington, DC: National Research Council. https://doi.org/10.17226/9598

Ockleford, C., Adriaanse, P., Berny, P., Brock, T., Duquesne, S., Grilli, S., ... Klein, M. (2018). Scientific opinion on the state of the science on pesticide risk assessment for amphibians and reptiles. EFSA J., 16(2), e05125. https://doi.org/10.2903/j.efsa.2018.5125

Rathjens, H., Oppelt, N., Bosch, D. D., Arnold, J. G., \& Volk, M. (2015). Development of a grid-based version of the SWAT landscape model. Hydrol. Proc., 29(6), 900-914. https://doi.org/10.1002/hyp.10197

Reichenberger, S., Sur, R., Kley, C., Sittig, S., \& Multsch, S. (2019). Recalibration and cross-validation of pesticide trapping equations for vegetative filter strips (VFS) using additional experimental data. Sci. Total Environ., 647, 534-550. https://doi.org/10.1016/j.scitotenv.2018.07.429

Rico, A., Van den Brink, P. J., Gylstra, R., Focks, A., \& Brock, T. C. (2016). Developing ecological scenarios for the prospective aquatic risk assessment of pesticides. Integ. Environ. Assess. Mgmt., 12(3), 510-521. https://doi.org/10.1002/ieam.1718

Rodea-Palomares, I., González-Pleiter, M., Gonzalo, S., Rosal, R., Leganés, F., Sabater, S., ... Fernandez-Pinas, F. (2016). Hidden drivers of low-dose pharmaceutical pollutant mixtures revealed by the novel GSA-QHTS screening method. Sci. Adv., 2(9), e1601272. https://doi.org/10.1126/sciadv.1601272

Sabbagh, G. J., Fox, G. A., Kamanzi, A., Roepke, B., \& Tang, J.-Z. (2009). Effectiveness of vegetative filter strips in reducing pesticide loading: Quantifying pesticide trapping efficiency. $J$. Environ. Qual., 38(2), 762-771. https://doi.org/10.2134/jeq2008.0266

Sabbagh, G. J., Fox, G. A., Muñoz-Carpena, R., \& Lenz, M. F. (2010). Revised framework for pesticide aquatic environmental exposure assessment that accounts for vegetative filter strips. Environ. Sci. Tech., 44(10), 3839-3845. https://doi.org/10.1021/es100506s

Schäfer, R. B., Liess, M., Altenburger, R., Filser, J., Hollert, H., Roß-Nickoll, M., ... Scheringer, M. (2019). Future pesticide risk assessment: Narrowing the gap between intention and reality. Environ. Sci. Europe, 31(1), article 21. https://doi.org/10.1186/s12302-019-0203-3

Senaviratne, G. M. M. M. A., Baffaut, C., Lory, J. A., Udawatta, R. P., Nelson, N. O., Williams, J. R., \& Anderson, S. H. (2018). Improved APEX model simulation of buffer water quality benefits at field scale. Trans. ASABE, 61(2), 603-616. https://doi.org/10.13031/trans.12655

Sittig, S., Sur, R., Baets, D., \& Hammel, K. (2020). Consideration of risk management practices in regulatory risk assessments: Evaluation of field trials with micro-dams to reduce pesticide transport via surface runoff and soil erosion. Environ. Sci. Europe, 32(1), article 86. https://doi.org/10.1186/s12302-02000362-1

Stone, W. W., Gilliom, R. J., \& Ryberg, K. R. (2014). Pesticides in U.S. streams and rivers: Occurrence and trends during 1992- 
2011. Environ. Sci. Tech., 48(19), 11025-11030. https://doi.org/10.1021/es5025367

Sur, R., Reichenberger, S., Srinivasan, P., Meyer, H., \& Kley, C. (2019). Effectiveness of vegetated filter strips based on modeling with VFSMOD or fixed reduction percentages from the European regulatory framework. Paper No. AGRO 302. Proc. ACS Meeting 258. Washington, DC: American Chemical Society.

Topping, C. J., Aldrich, A., \& Berny, P. (2020). Overhaul environmental risk assessment for pesticides. Science, 367(6476), 360-363. https://doi.org/10.1126/science.aay1144

Topping, C. J., Craig, P. S., de Jong, F., Klein, M., Laskowski, R., Manachini, B., ... van der Linden, T. (2015). Towards a landscape-scale management of pesticides: ERA using changes in modelled occupancy and abundance to assess long-term population impacts of pesticides. Sci. Total Environ., 537, 159169. https://doi.org/10.1016/j.scitotenv.2015.07.152

Topping, C. J., Dalby, L., \& Valdez, J. W. (2019). Landscape-scale simulations as a tool in multi-criteria decision making to support agri-environment schemes. Agric. Syst., 176, article 102671. https://doi.org/10.1016/j.agsy.2019.102671

UN. (2018). 2018 Revision of world urbanization prospects. Rome, Italy: United Nations, Department of Economic and Social Affairs.

USDA. (2005). Pest management (acre). Conservation Practice Standard Code 595. Washington, DC: USDA Natural Resources Conservation Service.

USEPA. (2019). Exposure assessment tools by tiers and types: Screening-level and refined. Washington, DC: U.S. Environmental Protection Agency. Retrieved from https://www.epa.gov/expobox/exposure-assessment-tools-tiersand-types-screening-level-and-refined

Verma, N., \& Bhardwaj, A. (2015). Biosensor technology for pesticides: A review. Appl. Biochem. Biotech., 175(6), 30933119. https://doi.org/10.1007/s12010-015-1489-2
Vermeulen, R., Schymanski, E. L., Barabasi, A.-L., \& Miller, G. W. (2020). The exposome and health: Where chemistry meets biology. Science, 367(6476), 392-396. https://doi.org/10.1126/science.aay3164

Vijver, M. G., Hunting, E. R., Nederstigt, T. A. P., Tamis, W. L. M., van den Brink, P. J., \& van Bodegom, P. M. (2017). Postregistration monitoring of pesticides is urgently required to protect ecosystems. Environ. Toxicol. Chem., 36(4), 860-865. https://doi.org/10.1002/etc.3721

Wang, R., Yuan, Y., Yen, H., Grieneisen, M., Arnold, J., Wang, D., ... Zhang, M. (2019). A review of pesticide fate and transport simulation at watershed level using SWAT: Current status and research concerns. Sci. Total Environ., 669, 512-526. https://doi.org/10.1016/j.scitotenv.2019.03.141

Webber, D. F., Bansal, M., Mickelson, S. K., Helmers, M. J., Arora, K., Gelder, B. K., ... Judge, C. J. (2018). Assessing surface flowpath interception by vegetative buffers using ArcGIS hydrologic modeling and geospatial analysis for Rock Creek watershed in central Iowa. Trans. ASABE, 61(1), 273-283. https://doi.org/10.13031/trans. 12350

Winchell, M. F., Peranginangin, N., Srinivasan, R., \& Chen, W. (2018). Soil and Water Assessment Tool model predictions of annual maximum pesticide concentrations in high-vulnerability watersheds. Integ. Environ. Assess. Mgmt., 14(3), 358-368. https://doi.org/10.1002/ieam.2014

Yagow, G., Wilson, B., Srivastava, P., \& Obropta, C. C. (2006). Use of biological indicators in TMDL assessment and implementation. Trans. ASABE, 49(4), 1023-1032. https://doi.org/10.13031/2013.20785

Yan, X., Li, H., \& Su, X. (2018). Review of optical sensors for pesticides. TrAC, Trends Anal. Chem., 103, 1-20. https://doi.org/10.1016/j.trac.2018.03.004

Zhang, X. (2019). Environmental DNA shaping a new era of ecotoxicological research. Environ. Sci. Tech., 53(10), 56055612. https://doi.org/10.1021/acs.est.8b06631 